\title{
Knowledge, Attitude, and Behavioural Practice of Elementary Teacher of ADHD Children: Impact of an Educational Intervention
}

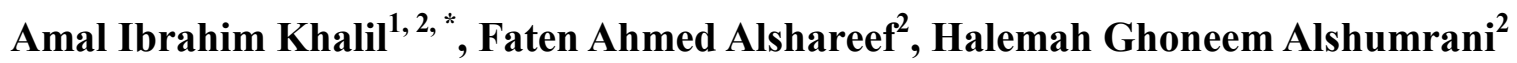 \\ ${ }^{1}$ Psychiatric and Mental Health Nursing, Faculty of Nursing, Menofyia University, Shebin Elkom, Egypt \\ ${ }^{2}$ College of Nursing, King Saud University for Health Sciences, Jeddah, Saudi Arabia
}

Email address:

khalila@ksau-hs.edu.sa (A. I. Khalil), amalkhali134@yahoo.com (A. I. Khalil)

${ }^{*}$ Corresponding author

To cite this article:

Amal Ibrahim Khalil, Faten Ahmed Alshareef, Halemah Ghoneem Alshumrani. Knowledge, Attitude, and Behavioural Practice of Elementary Teacher of ADHD Children: Impact of an Educational Intervention. American Journal of Nursing Science. Special Issue: Disability from Different Nursing Perspectives. Vol. 8, No. 6, 2019, pp. 329-341. doi: 10.11648/j.ajns.20190806.17

Received: October 15, 2019; Accepted: November 6, 2019; Published: November 20, 2019

\begin{abstract}
Background: According to Saudi Arabia Attention deficit hyperactivity disorder (ADHD) Society, ADHD is one of the most common psychiatric disorder among children and affect both gender with total prevalence of male: $7.4 \%$ and female: $4.2 \%$ in Jeddah city. The aim was to investigate the effectiveness of an educational program on exchanging elementary school teachers' knowledge, attitudes and behavioral practices toward ADHD children. Methods: A quasi-experimental, quantitative, (pre/ post one group) research design was used with 57 elementary teachers recruited conveniently from 4 schools located in Jeddah city and affiliated to Ministry of Education, Saudi Arabia. Data were collected by using 3 main tools which are The Knowledge Attention Deficit Disorders (KADDS) scale, The teacher attitude towards inclusion scale (TAIS), and Teacher Intervention Survey which was used to assess teachers' perceived familiarity with interventions commonly recommended with students with ADHD. The results: Nearly half of the sample were aged between $31-40$ years with total mean score (35.86 \pm 7.09$)$ and $(80.0 \%)$ of them had bachelor's degree in general education and there is a significant difference between pre knowledge assessment (11.8 \pm 5.9$)$ compared with post (18.2 \pm 4.9$)$ with highly significant difference $t=-6.81$ at P.V $(0.000)$ as well the difference between pre and post behavioral practices of studied sample at $p=0.000$. Conclusion: the present study suggests that a brief professional educational intervention can be utilized to greatly increase teachers' ADHD knowledge, providing a cost-effective, practical solution to address the well-evidenced gap in teachers' training and knowledge about the disorder. Whereas improving attitudes was minor with no significant difference between pre/post assessment. Therefore, it is recommended to incorporate ADHD training programs into teacher-training curricula either in elementary special or general education, with regular reinforcement through in-service training.
\end{abstract}

Keywords: ADHD, Behaviors Strategy, KADDS, Program, Teacher Proficiency Skills

\section{Introduction}

Early childhood is one of the most important developmental stage of any person`s life, as the personality starts to develop through the child interaction with the environment. The mental process (attention) plays an important role in his/her intellectual growth. Some of the children may suffer from deficit in their attention that associated with hyperactivity. This condition may lead them to do an inappropriate behavior for example, they cannot focus and complete one task and they cannot set still, or they do unfocused and impulsive [1]. According to Saudi Arabia ADHD Society, Attention deficit hyperactivity disorder (ADHD) is one of the most common psychiatric disorder among children and affect both gender with total prevalence of male: $7.4 \%$ and female: $4.2 \%$ in Jeddah city behavior [2]. ADHD one of a behavioral and intellectual disorders that can interfere with the child life and relationship with their peer. 
Unfortunately, ADHD is not early detected among children until they started their studying life due to lack of parents and teacher awareness' regarding these serious disorders [3].

Attention deficit hyperactivity disorder (ADHD) is defined by American Psychiatric Association as neurobiological or neurodevelopmental disorder which has negative affect on the development of social, emotional, cognitive skills in early childhood years [4]. Children who suffer from ADHD characterized by deficit in cognitive, behavior and emotion [2]. They also have a significance problem related to their hyperactivity and impulsivity [1]. According to Diagnostic and Statistical Manual of Mental Disorders 5th edition (DSM5), several types of ADHD were found including: ADHD predominantly inattentive presentation (ADHD-PI), ADHD predominantly hyperactive-impulsive presentation (ADHD-PHI) and ADHD combined presentation- inattentive and hyperactive- impulsive- (ADHD-C). Naturally the children are differing in way of behaviors, so the (DSM5) placed some criteria and symptoms to diagnose the child with ADHD. These symptoms should be six or more of them last for six months. These criteria are: (a) makes careless mistakes/lacks attention to detail. (b) Difficulty sustaining attention; (c) Does not seem to listen when spoken to directly; (d) Fails to follow through on tasks and instructions:(e) Exhibits poor organization. (f) Avoids or dislikes tasks requiring sustained mental effort; (g) Loses when remaining seated is expected; (j) Experiences feelings of restlessness;(k) Has difficulty engaging in quiet, leisurely activities; (l) Talks excessively and blurts out answers; (m) Has difficulty waiting their turn and interrupts or intrudes on others $[4,5]$.

A lot of researches were published in the area of ADHD have focused on etiology, assessment, treatment of this disorder and children educational settings. However, only a small number of studies have been conducted to examine teachers' knowledge, attitudes and their behavioral and practices of ADHD investigate the effectiveness of and educational program.

Teacher play important role in general and specifically with ADHD child. Teacher are responsible for the child's live inside the class room. In addition, the teacher has different task more than education, she can build warm environment, become a role model for the child because they stay long time with them.

This time may have negative or positive impact on child depending on the teacher [6]. Assess the child and detect any trouble when the child behavior change [6]. Natural structure of school environment may let the teacher to be the first one who notice the hyperactivity or inattentive [7]. Teachers have also to accurately differentiate between symptoms of ADHD and merely hyperactive because of environmental destruction [7]. Early detection by teachers will help on early management which will prevent complication [8]. More specifically, teacher who are dealing with ADHD children should have special educational qualification as they have different role, such as, accommodations to make the teaching easier, give instruction to control the child behavior, and intervene to decrease the destruction that occur by this child [9]. Besides, referral to psychologists since the child behavior is interfering with classroom behavior [10]. Additionally, the teachers are required to interact with the parents in order to provide appropriate and correct information about the diagnosis of their children, methods of communication and behavioral management [8].

It was reported by evidence-based research that the more the exposure or experience with ADHD child, the more the knowledge and skill will be advanced [10]. Previous studies in Nigeria and other countries have found that teachers have negative attitude toward students with ADHD which may give rise to self-disparagement and lack of interest in their classes due to lack of their knowledge and skills regarding how to manage the ADHD children [11]. In the same vein, Lasisi et al. [11] reported that teachers' level of education, years of experience, and training are among the factors that influence the behavior and attitude of teachers toward ADHD child. Therefore, Teachers need to know how to apply their knowledge in order to have successful results and should has positive attitude with child who diagnosed with ADHD to act correctly and be away from negative evaluation because teachers' attitudinal practice may interfere with the ability to evaluate the child behavior [11].

The reports from previous studies which were used educational program showed that the teachers had lack of knowledge of ADHD in pre assessment interventions while their knowledge, attitudes and behavioral interventions were changed after teaching program conducted to them of and there were statistically significant changes at their postintervention than pre-intervention regarding participants 'knowledge, attitude, and behavior management strategies. Additionally, educational interventions were proved its effectiveness with elementary teachers of primary schools on improving their knowledge, change attitude and behavior management strategies into more positively one [12]. Moreover, the other study was done in Kaduna and North West Nigeria showed that there is a significance differences between the mean score and positive out comes after educational program and significant differences in the postintervention scores on all outcome which are knowledge and attitudes [13].

\subsection{Research Problem}

Many teachers who had training in management of school classroom are quite expert in developing and implementing programs for students with ADHD. However, because most children with ADHD are not enrolled in special education services, their teachers will most often be regular education teachers who may have little knowledge about ADHD or behavior modification and will need assistance in learning and implementing the necessary programs [14]. For that reason research was conducted an educational intervention for elementary school teachers and investigating its effectiveness in improving their knowledge, attitudes and practices of ADHD children. 


\subsection{Research Questions}

The current study intended to answer the following questions:

1. What is the teachers' knowledge in pre and post assessment as it was measured with Knowledge Attention Deficit Disorders (KADDS) scale?

2. What are the teachers' attitudes toward ADHD children in pre and post as it was assessed by The teacher attitude towards inclusion scale (TAIS)?

3. What are the behavioral strategies used by the teachers in pre and post as it was measured by intervention survey scale?

4. What are the correlation between teachers demographic background with their knowledge, attitude and behavioral practices total mean score in pre and post assessment?

\subsection{Research Aim}

This study was aimed to investigate the effectiveness of an educational program on exchanging elementary school teachers' knowledge, attitudes and behavioral practices toward ADHD children. More specifically, the study looked at:

1. Assess elementary school teachers existing knowledge, attitudes and behavioral practices of ADHD children (pre/post).

2. Examine the association between teachers demographic characteristics and their knowledge, attitudes and behavioral practices of ADHD children

\subsection{Research Hypothesis}

1. H.1 Elementary school teachers' knowledge, attitudes and behavioral practices total scores will be increased after conducting the interventional program.

2. H.2 Elementary school teachers' knowledge, attitudes and behavioral practices total score will remain as in pre assessment after conducting the program.

\subsection{Significance of the Study}

The prevalence of ADHD was $11.6 \%$ as reported by Homidi et al [2], and Alhraiwil. et al [13] who had done a systematic review and found that the prevalence of ADHD was ranged between $1.3 \%-16 \%$ which indicate the higher prevalence among school age children aged between 6-12 years old [13]. To the best knowledge, the previous studies which were done in Saudi Arabia focused only in assessing the teacher knowledge, attitude, and their behavior toward ADHD children, and no studies were conducted to assess the effectiveness of an educational intervention on increasing the teacher knowledge and enhance their attitude and behavioral practice, therefore, the researcher think about developing an educational interventions targets the elementary school teachers and evaluate its effectiveness in developing their knowledge, attitudes and practices of ADHD children.

\section{Methodology}

\subsection{Research Design}

A quantitative quasi-experimental, one-group, pre-posttest was used to achieve the objectives of this study

\subsection{Research Setting}

The study was conducted in 4 elementary schools, two were governmental and the other were private sector located in Jeddah, Saudi Arabia. It includes: Zubeida 115 Elementary School for Girls affiliated to National Guard health affairs related to housing Compound in Bani Malik district, Jeddah, Saudi Arabia. This school had 27 elementary teacher, 5 teachers are qualified to work with children with educational disabilities. This school provides in-service education for 240 saudi children. The Second school was House Greats private Primary School for girl affiliated to ministry of education, located at Abu Al Hassan Alsuqeli district, has 16 elementary teacher, 11 general teacher and 5 special education for learning disabilities. While, the Third school was Elementary 194, located at Al Amir Abdoulmajeed District, this school has 34 elementary school serving 846 primary school children, among of them one teacher assigned for special education. The fourth school was sun shine private primary school affiliated to ministry of education located at Alkhaldia, district, Jeddah Saudi Arabia.

\subsection{Population and Sample Size}

All female teacher of the four selected elementary schools and who were willing to participate in this study. Their minimum number was 50 teachers, age ranged from $22-60$ years old, and had at least one year or more teaching experiences with ADHD children.

\subsection{Data Collection Tools}

Tools of the study consisted of 4 main parts:

1. Demographic and personal characteristics of the teachers such as, age, gender, marital status level of education, years of experience and did they attend any training workshop about ADHD.

2. The Knowledge Attention Deficit Disorders (KADDS) tool: this tool measures teachers' understanding and perceptions of ADHD [15]. The scale consists of 36 items. The responses were indicated as 'incorrect', 'correct' and 'don't know' responses. Correct responses were indicated with a '1', while incorrect and don't know responses were indicated with a ' 0 '. The Alpha coefficient for the current study was. 89 for the total items. This alpha score indicates good reliability of the instrument and similar results were found locally [16] and internationally $[17,18]$

The KADDS consists of three subscales. The first subscale measured general information related to ADHD, using 15 items. Items on the general knowledge subscale included: "Attention Deficit Disorder occurs in approximately 15\% of all school-aged children", and "it is possible for an adult to be diagnosed with ADHD" [15]. The second subscale measures 
symptoms/diagnosis of ADHD using nine items. Items on the symptoms/diagnosis knowledge subscale included "Symptoms must not be present before age seven to be diagnosed with ADHD" and "children diagnosed with an attention deficit disorder tend to have poor concentration" [15] ADHD, using 12 items. Items on the treatment knowledge subscale included "Stimulant medication increases concentration" and "Electroconvulsive Therapy (ECT) is an effective treatment for Attention Deficit Disorder"[15].

3. The teacher attitude towards inclusion scale (TAIS) developed by Soodak, Podell, \& Lehman [19] was used in the present study. The scale was used to assess teachers' attitude toward having student suffering from ADHD in their regular classrooms. The subjects will be given a short scenario, which show that their leader informed them that they will include student who have special needs in their classrooms. Each one of them will handle one student with different disability which is physical disability, behavioral disorder, intellectual disability, learning difficulties, and hearing impairment. The scale composed of 17 pairs of adjectives refer to teachers possible feeling toward including ADHD child in their classroom, the participants answer will be rated on 4 points Likert-type scale. The scale will be rated for each feeling from $1-4$ as $1=$ "accepting" to $4=$ "opposing" or 1 = "comfortable" to 4 = "uncomfortable"). The questionnaire includes 11 items with four response scale. The minimum score is 11 (negative attitude), and the maximum score is 44 (positive attitude).

In this study an adopted planned hypothetical vignettes which divided into two parts, the first part describes students who meet the DSM-IV criteria for $\mathrm{AD} / \mathrm{HD}$ inattentive subtype (AD/HD-I) in primary school. The second part represent students with behaviors related to $\mathrm{AD} / \mathrm{HD}$ hyperactivity/ impulsive subtype (AD/HD-HI). The participants were given the prepared vignettes to read it and respond by expressing their feeling. Alamri [6] used the scenario and added to each vignette: "suppose that your school decides to include (Salem or Salma) in your classroom". This addition was used in the current study as the tool was used with Saudi population.

4. Teacher Intervention Survey. A modified version of selfreported teacher questionnaire developed by Matlock [20] was used to assess teachers' perceived familiarity with interventions commonly recommended for use with students with ADHD. Teachers will indicate their responses on a Likert scale from one (low response) to five (high response) "how knowledgeable they are regarding," "how effective they perceive," and "how willing they would be" to implement various interventions in their classrooms for students with ADHD. Reliabilities for the six items for each intervention on the Teacher Intervention Survey are reported by SMALL [21] in his thesis as Coefficient alpha ranged from.79 (Teacher attention) to.96 (Use of cues, prompts, and attention checks) for the main study, with nine of the 12 interventions having reliabilities greater than.90. The six items for each intervention consisted of a single item for knowledge, skill, effectiveness, acceptability, time/resources, and use.
Additionally, the reliabilities for the three-item barriers variable ranged from.72 (Token economy) to.94 (Use of cues, prompts, and attention checks) for the main behavioral interventions used with ADHD children in the classroom.

\subsection{Reliability and Validity}

The study instruments were translated into Arabic language and back translated into English language. Back translation aimed at verifying whether the translation covers all aspects of the original English version of the questionnaire or not. Then to ensure the face validity and reliability of the final translated Arabic version of the questionnaires were evaluated by a panel of experts who were selected based on their qualifications and experience in nursing research and education. the validity of the questionnaires was calculated and reported 0.81 for KADDS, 0.79 for TAIS and 0.77 for intervention practices survey.

\subsection{Pilot Study}

After the validity was confirmed for the Arabic version of questionnaires, the tools were piloted and tested by 10 teachers to identify ambiguities in questions, time required for completing the questionnaire, and any difficulties that might be encountered by the participants in reading or understanding the questionnaires. Those 10 teachers were included within the actual sample due to the limited number of studied population. In the present study, the Cronbach's alpha coefficient for the KADDS total scale was $0.73,0.84$ for TAIS and 0.75 which represents good reliability [22].

\subsection{Data Collection Procedure}

After the approval of the proposed study was received from KAIMRC and IRB, the data were collected during the academic year 2018/2019 spring semester. The participants were asked to sign the informed consent form before starting the program, and to fill the questionnaires before, and after the educational training program. The program was developed based on extensive review of literature. After the conduction of the program the teachers were expected to:

1. Identify the symptoms, and clinical manifestations of ADHD children.

2. List risk factors, causes of $\mathrm{ADHD}$, and the treatment modalities both pharmacological and nonpharmacological.

3. Describe the warning signs of ADHD appear on students having ADHD risk factors.

4. Apply the different professional behavioral interventions to manage ADHD including (role of teachers in early detection of ADHD children, how they can do referral.

5. Use different ways of interactions with the families of ADHD children besides the reinforcement of using behavioral strategies such as; positive and negative reinforcement, home-based contingencies,

6. Apply physical arrangement and restructure of the class room environment, and use varied presentations and 
format of learning materials and policy and regulations during final exams and quizzes.

7. The program was conducted on one day 6 hours divided into two session, every session was 45 minutes to 1 hours as following:

8. The first session was about knowledge and attitude toward ADHD children which was include ADHD definition, symptoms and clinical manifestation, causes and treatment modalities (pharmacological and nonpharmacological).

9. The second session was discussed ADHD management, such as teacher attention, Token economy, Response cost, Time-out from positive reinforcement, homebased contingencies, structure, physical arrangement, varied presentation and format of materials, and use of cues, prompts and attention. The participant was asked to fulfill the questioner before conducted the program, after that we were distribute the posttest assessment questionnaires.

\subsection{Methods of Instructions}

The sessions were presented the teachers with booklets, brochures and audio-visual materials designed for management of ADHD. Role play, modeling, demonstration and redemonstration was used to teach the behavioral interventions.

\subsection{Data Management}

After that the data was coded and analyzed using SPSS version 22.0. Data was presented

using descriptive statistics for discrete variables in the form of frequencies and percentages, and for interval and ratio variables in the form of means and standard deviations. A paired $t$ test was used to analyze the total scores of the participants' responses on the pre-test and the post-test (i.e., before and after the educational training program). Participants' sociodemographic and knowledge, attitudes and practices differences analyzed by using Chi Square test $(\chi 2)$. Pearson $r$ used to test the correlation between their knowledge and sociodemographic variables. The significance level tested at $\mathrm{p}<0.05$

\subsection{Ethical Considerations}

This study was submitted to the committee of the research unit to be reviewed and approved a by KAIMARC, and IRB, an agency whose duty was to review ethical considerations and ensure that all research participants were protected against harm. This study records were kept private. In any report which will be published, the researchers were not include any information that were enable you to be identified by others. Research records were kept confidential; the records were only accessed by researchers. The participants were informed that their participation is voluntary, and they have the right to drop from the study anytime without any penalty.

\section{Findings}

Table 1 showed that nearly half of the sample were aged between $31-40$ years with total mean score (35.86 \pm 7.09$)$ and $(80.0 \%)$ of them had bachelor's degree in education. As regard to teachers pervious information with ADHD (.61.4\%) (75.4) and, (50.9) didn't learn during their school, didn't attend an in-service training, didn't read books, and didn't know any ADHD children respectively. On the other hand, almost two third $(63.2 \%)$ and (59.6) of the sample read articles and pamphlets about ADHD respectively.

Table 1. Distribution of studied subjects according to their demographic background $(N=57)$.

\begin{tabular}{|c|c|c|c|}
\hline Variable & Frequency & $\%$ & $\mathbf{M} \pm \mathbf{S D}$ \\
\hline \multicolumn{4}{|l|}{ Age: } \\
\hline $23-30$ years & 19 & 33 & \multirow{3}{*}{$35.86 \pm 7.09$} \\
\hline 31-40years & 28 & 49.1 & \\
\hline $41-50$ years & 10 & 25.5 & \\
\hline \multicolumn{4}{|c|}{ Level of education } \\
\hline Bachelor & 46 & 80.7 & \\
\hline Diploma & 5 & 8.8 & \\
\hline Master & 4 & 7.0 & \\
\hline \multicolumn{4}{|c|}{ Did you learn about ADHD during your teacher training? } \\
\hline No & 35 & 61.4 & \\
\hline yes & 22 & 38.6 & \\
\hline \multicolumn{4}{|c|}{ Attended an in-service presentation on ADHD? } \\
\hline No & 43 & 75.4 & \multirow{3}{*}{$1.28 \pm 0.559$} \\
\hline Yes & 13 & 22.8 & \\
\hline Nothing & 1 & 1.8 & \\
\hline No & 37 & 64.9 & \multirow[t]{2}{*}{$1.35 \pm 0.481$} \\
\hline yes & 20 & 35.1 & \\
\hline \multicolumn{4}{|c|}{ Read any articles on ADHD? } \\
\hline No & 21 & 36.8 & \multirow[t]{2}{*}{$1.63 \pm 0.487$} \\
\hline yes & 36 & 63.2 & \\
\hline \multicolumn{4}{|c|}{ Read any pamphlets/handouts on ADHD? } \\
\hline No & 23 & 40.4 & \multirow[t]{2}{*}{$1.60 \pm 0.495$} \\
\hline yes & 34 & 59.6 & \\
\hline
\end{tabular}




\begin{tabular}{lccc}
\hline Variable & Frequency & \% & M \pm SD \\
\hline Do you know anyone outside of school who has ADHD (either child or adult)? & & \\
No & 29 & 50.9 & $1.49 \pm 0.504$ \\
yes & 28 & 49.1 & \\
\hline
\end{tabular}

Figure 1 indicated the comparison between correct and incorrect answered in pre and post knowledge of ADHD, the results showed statistically improvement in both the correct and incorrect after the intervention program as $\mathrm{t}=-6.810$ at $\mathrm{P}=.000$.

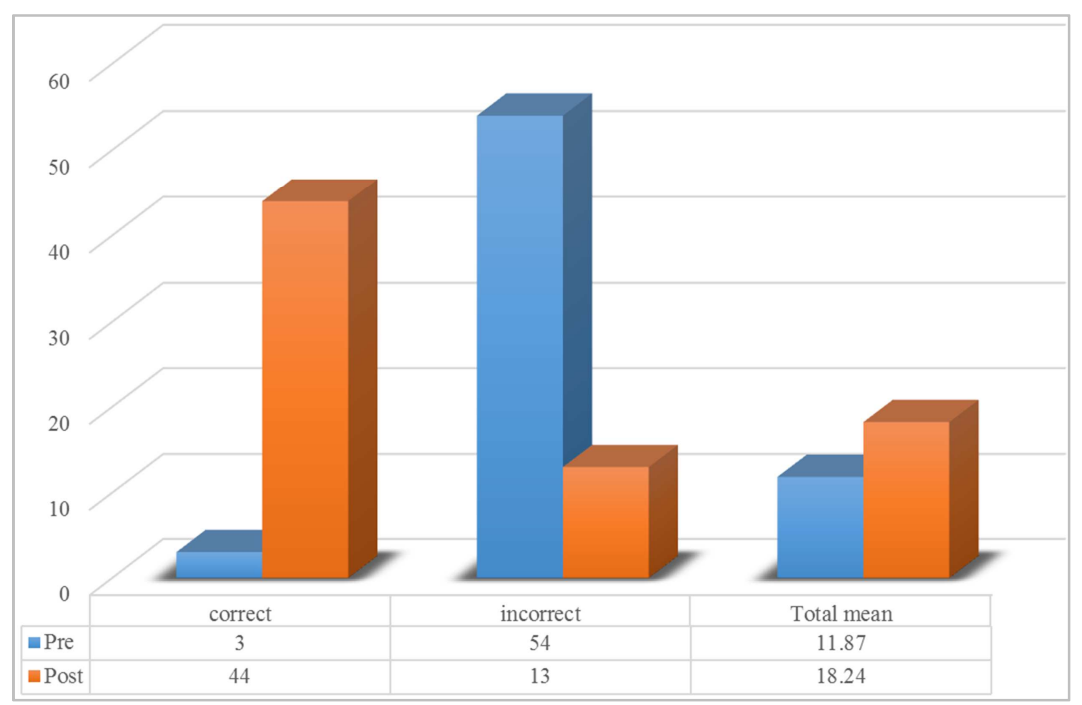

Figure 1. Comparison between correct and incorrect answers among Participant related to ADHD knowledge.

Table 2 illustrated the at there were significant difference between pre knowledge assessment (11.8 \pm 5.9$)$ compared with post $(18.2 \pm 4.9)$ with highly significant difference $t=-$ 6.81 at $\mathrm{P} . \mathrm{V}(0.000)$ as well the difference between pre and post behavioral practices of studied sample at $\mathrm{p}=0.000$. On the other hand, the participant attitudes were $(45.157 \pm 8.019)$ in pre assessment compared with $(46.4 \pm 4.7)$ at post assessment with no significant difference at $\mathrm{p}=0.250$.

Table 2. Comparison between pre and post assessment of studied group as regard to ADHD knowledge, attitudes and behavioral practices. ( $n=57$ ).

\begin{tabular}{lllll}
\hline \multirow{2}{*}{ Variable } & $\mathbf{M} \pm$ SD & & t & \\
\cline { 2 - 3 } & Pre & Post & -6.81 & \\
\hline Total knowledge & $11.8 \pm 5.9$ & $18.2 \pm 4.9$ & 1.161 & 0.000 \\
Total attitude & $45.157 \pm 8.019$ & $46.4 \pm 4.7$ & -8.118 & 0.250 \\
Total behaviour & $119.9 \pm 34.5$ & $176.07 \pm 36.98$ & 0.000 & \\
\hline
\end{tabular}

Table 3 Compared between total $\mathrm{M} \pm \mathrm{SD}$ of Pre and post all behavioral strategies which were used by the teachers with ADHD children including; (Teacher attention, Token economy, Response cost, Time-out from positive reinforcement, Home-based contingencies, Structure, Physical arrangement, Varied presentation and format of information). The results revealed that, there were significant difference and change between pre and post assessment in relation to all strategies at $\mathrm{p}=.000$, except for time-out technique as a positive reinforcement strategy as it was indicated that there is no significant change between pre and post teacher performance as $\mathrm{t}=-1.742$ at $\mathrm{p}=.087$.

Table 3. Comparison between Pre $M \pm S D$ and post $M \pm S D$ of all behavioral strategies among studied subjects (N=57).

\begin{tabular}{|c|c|c|c|c|}
\hline \multirow{2}{*}{ Behavioral strategies } & \multicolumn{2}{|l|}{ Mean \pm SD } & \multirow[b]{2}{*}{$\mathbf{t}$} & \multirow{2}{*}{ Sig } \\
\hline & Pre & Post & & \\
\hline Teacher attention & $15.83 \pm 6.160$ & $23.41 \pm 6.83$ & -5.809 & .000 \\
\hline Token economy & $17.08 \pm 6.71$ & $23.91 \pm 5.55$ & -6.109 & .000 \\
\hline Response cost & $14.72 \pm 5.81$ & $21.70 \pm 6.06$ & -6.178 & .000 \\
\hline Time-out from positive reinforcement & $14.23 \pm 6.60$ & $16.75 \pm 8.77$ & -1.742 & .087 \\
\hline Home-based contingencies & $13.8929 \pm 6.53$ & $17.89 \pm 8.83$ & -2.823 & .007 \\
\hline Structure & $14.4286 \pm 5.61$ & $23.53 \pm 6.80$ & -7.154 & .000 \\
\hline Physical arrangement & $14.9825 \pm 6.63$ & $24.45 \pm 6.32$ & -6.842 & .000 \\
\hline Varied presentation and format of materials & $16.0175 \pm 7.14$ & $23.61 \pm 6.57$ & -6.141 & .000 \\
\hline Use of cues, prompts and attention & $17.5263 \pm 7.387$ & $24.00 \pm 6.82$ & -4.746 & .000 \\
\hline Brief academic tasks interspersed with Passive tasks & $15.51 \pm 7.21$ & $21.51 \pm 6.92$ & -5.138 & .000 \\
\hline Peer tutoring & $13.49 \pm 6.87$ & $19.01 \pm 7.57$ & -3.969 & .000 \\
\hline Self-management & $14.50 \pm 6.92$ & $23.21 \pm 7.02$ & -7.344 & .000 \\
\hline
\end{tabular}


Table 4 presented the comparison between correct and incorrect answered of ADHD knowledge pre and post assessment the comparison was about general knowledge, symptoms, and treatment of ADHD. The result showed there was significant change between pre and post assessment of general knowledge, symptoms identifications and treatment modalities as $\mathrm{t}=-(6.307)(-4.062)$, and (-4.982) respectively at $\mathrm{p}=.000$.

Table 4. Comparison between pre and post assessment correct and incorrect responses among studied participant on the KADHD knowledge symptoms, and treatment modalities $(N=57)$.

\begin{tabular}{|c|c|c|c|c|}
\hline \multirow{2}{*}{ Knowledge of ADHD } & \multicolumn{2}{|l|}{$\mathbf{M} \pm \mathbf{S D}$} & \multirow{2}{*}{$\mathbf{t}$} & \multirow{2}{*}{ Sig } \\
\hline & Pre & Post & & \\
\hline General knowledge of ADHD & $5.19 \pm 3.297$ & $8.1053 \pm 2.64$ & -6.307 & .000 \\
\hline Symptoms of ADHD & $4.2281 \pm 2.146$ & $5.6842 \pm 1.681$ & -4.062 & .000 \\
\hline Treatment Modalities & $2.4035 \pm 1.521$ & $3.7368 \pm 1.408$ & -4.982 & .000 \\
\hline
\end{tabular}

Figure 2 exhibited the difference between pre and post total mean score of the teachers as regard to their knowledge KADHD scale. It is shown that the total pre of the participant knowledge was 5.19 compared with 8.10 and 4.22 compared with 5.68 for ADHD symptoms identifications. Additionally, the total mean of identifying treatment modalities was 2.40 in pre compared with 3.73 in the post intervention program.

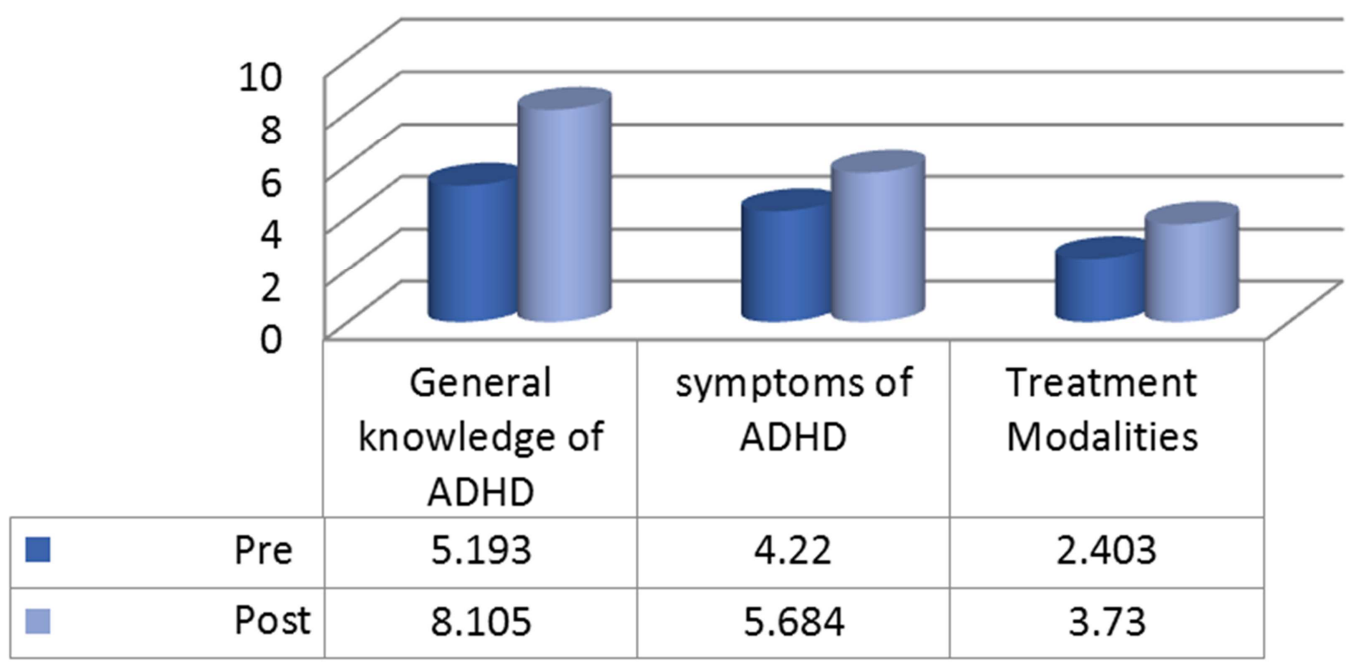

Figure 2. Comparison between total mean score of pre and post knowledge scale.

Table 5 illustrated the correlation between teacher demographic background and their measurements scale pre/post intervention. The result revealed that, there were no significant relation between all teachers demographics with their knowledge, attitude, and behavioral in both pre and post, except for who attending an in-service presentation on ADHD in post behavioral practice assessment at $\mathrm{p}=.004$.

Table 5. Relationship between demographic with knowledge, attitude, and behavioral practice pre and post $(n=57)$.

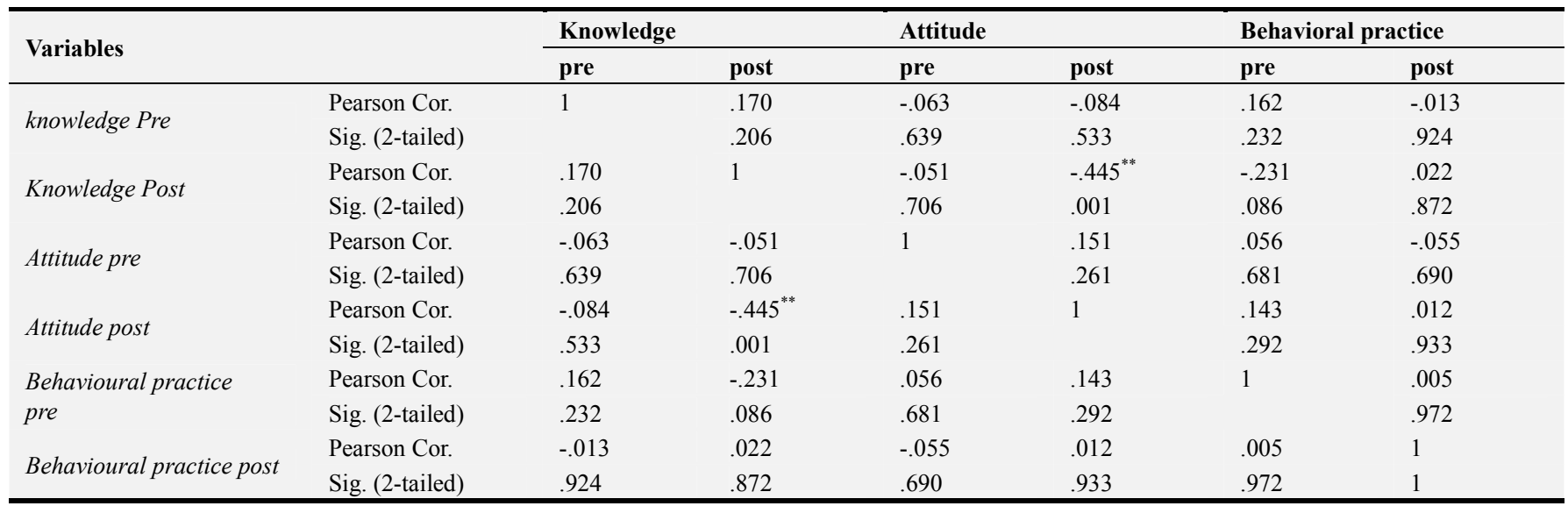


Table 6 presented the correlation between measurement scales (KDDH, attitudes, and behavioral practices) in pre and post interventions. The results revealed that there was no significant correlation between all measurements scale except for the presence of statistically significant correlation between teachers' attitude in post assessment with their behavioral practices in post assessment at $\mathrm{r}=.012$ and their behavioral practices in pre assessment with their post assessment at $\mathrm{r}=.005$.

Table 6. Correlation between measurements scales (KDDH, attitudes, and behavioral practices) in pre and post interventions. ( $n=57)$.

\begin{tabular}{|c|c|c|c|c|c|c|}
\hline \multirow{2}{*}{ Variable } & \multicolumn{2}{|c|}{ Knowledge } & \multicolumn{2}{|l|}{ Attitude } & \multicolumn{2}{|c|}{ Behavioral practice } \\
\hline & pre & post & Pre & Post & Pre. & post \\
\hline \multicolumn{7}{|l|}{ Age } \\
\hline 1. Mean & 63.327 & 30.181 & 59.884 & .56 .439 & 59.329 & 44.33 \\
\hline 2. Frequency & 1.491 & .523 & 1.298 & 1.235 & 1.982 & .599 \\
\hline 3. Sig & .145 & .912 & 244 & .285 & .071 & .891 \\
\hline \multicolumn{7}{|l|}{ Total number of years of teaching experience? } \\
\hline 1. Mean & 78.513 & 53.205 & 80.599 & 91.474 & 87.653 & 74.496 \\
\hline 2. Frequency & 1.038 & .622 & 1.075 & 1.400 & 1.771 & .962 \\
\hline 3. Sig & .450 & .839 & .411 & .187 & .116 & .566 \\
\hline \multicolumn{7}{|c|}{ How many students with documented ADHD have you taught? } \\
\hline 1. Mean & .897 & .509 & .309 & .601 & .624 & .601 \\
\hline 2. Frequency & 2.339 & .849 & .446 & 1.078 & 1.302 & 1.110 \\
\hline 3. Sig & .013 & .621 & .962 & .416 & .291 & .447 \\
\hline \multicolumn{7}{|c|}{ If you've had students with ADHD in your classroom } \\
\hline 1. Mean & .676 & .614 & .811 & .325 & .601 & .695 \\
\hline 2. Frequency & 1.043 & .909 & 1.369 & .357 & .801 & 1.191 \\
\hline 3. Sig & .445 & .561 & .205 & .994 & .722 & .389 \\
\hline \multicolumn{7}{|l|}{ Attended an in-service presentation on ADHD? } \\
\hline 1. Mean & .403 & .297 & .271 & .360 & .235 & .379 \\
\hline 2. Frequency & 1.558 & .934 & .820 & 1.300 & .479 & 4.545 \\
\hline 3. Sig & .120 & .536 & .662 & .241 & .969 & .004 \\
\hline \multicolumn{7}{|l|}{ Read any books on ADHD? } \\
\hline 1. Mean & .279 & .181 & .149 & .182 & .261 & .202 \\
\hline 2. Frequency & 1.374 & .721 & .557 & .676 & 1.568 & .570 \\
\hline 3. Sig & .198 & .749 & .903 & .838 & .167 & .911 \\
\hline \multicolumn{7}{|l|}{ Read any articles on ADHD? } \\
\hline 1. Mean & .198 & .239 & .249 & .739 & .234 & .226 \\
\hline 2. Frequency & .762 & 1.015 & 1.078 & .197 & .936 & .774 \\
\hline 3. Sig & .741 & .460 & .407 & .776 & .585 & .741 \\
\hline Read any pamphlets/handouts on ADHD? & .323 & .286 & .205 & .182 & .236 & .229 \\
\hline 1. Mean & 1.631 & 1.247 & .780 & .623 & .873 & .734 \\
\hline $\begin{array}{l}\text { 2. Frequency } \\
\text { 3. Sig }\end{array}$ & .098 & .279 & .703 & .883 & .649 & .778 \\
\hline \multicolumn{7}{|l|}{ Watched any television programs on ADHD? } \\
\hline 1. Mean & .289 & .219 & .194 & 174 & .288 & .235 \\
\hline 2. Frequency & 1.322 & .859 & .728 & .582 & 1.973 & .807 \\
\hline 3. Sig & .227 & .611 & .756 & .913 & .072 & .710 \\
\hline \multicolumn{7}{|c|}{ Searched the internet for information on ADHD? } \\
\hline 1. Mean & .192 & .249 & .192 & .239 & .234 & .261 \\
\hline 2. Frequency & .727 & 1.074 & .748 & 1.014 & .936 & 1.569 \\
\hline 3. Sig & .777 & .408 & .737 & .478 & .585 & .202 \\
\hline \multicolumn{7}{|c|}{ Do you know anyone outside of school who has ADHD (either child or adult)? } \\
\hline 1. Mean & .394 & .264 & .238 & .241 & .192 & .256 \\
\hline 2. Frequency & 2.313 & 1.053 & .911 & .914 & .473 & 1.023 \\
\hline 3. Sig & .014 & .426 & .567 & .584 & .971 & .515 \\
\hline \multicolumn{7}{|c|}{ What do you think is the most appropriate educational placement for a student with ADHD? } \\
\hline 1. Mean & .596 & .347 & .526 & .497 & .578 & 476 \\
\hline 2. Frequency & 1.226 & .586 & .998 & .904 & 1.352 & .652 \\
\hline 3. Sig & .290 & .869 & .481 & .596 & .262 & .849 \\
\hline
\end{tabular}




\section{Discussion}

This quasi experimental study aimed at evaluating the effectiveness of an educational program in improving Knowledge, attitude and behavioral practice among Saudi elementary school teachers toward ADHD children in Jeddah, Saudi Arabia. It was hypothesized that teachers Knowledge, attitude and behavioral practice toward ADHD children will be improved after conducting the educational program. The current study results revealed that the program was effective in exchanging knowledge, and behavioral practices of the studied subjects as it was indicated that there is a significant difference between pre knowledge assessment (11.8 \pm 5.9$)$ compared with post (18.2 \pm 4.9$)$ with highly significant difference $\mathrm{t}=-6.81$ at $\mathrm{P} . \mathrm{V}(0.000)$ as well the difference between pre and post behavioral practices of studied sample at $p=0.000$. Similarly, the results of the current study were supported with the results of many studies that demonstrate the effectiveness of brief interventions to improve teacher knowledge of ADHD [31]. The results of this study was congruent with khalil and Abdelwahab [23], Latouche and Gascoign [24], Wienen et al. [25], Veenman, Luman,\& Oosterlaan [26] and White et al. [27], who showed that average scores of correct response in pre educational program was $(35 \pm 23.72)$ compared with post $(52 \pm 23.74)$ at $\mathrm{p}<.001$.

On the other hand, the participant attitudes was slightly changed toward ADHD, but with no significant difference as the pre assessment was (45.157 \pm 8.019$)$ compared with $(46.4 \pm 4.7)$ at their post assessment with no significant difference at $p=0.250$. This results was supported by Lasisi et al, [11] who found that their interventional program showed moderate to large effect sizes with significant increase in knowledge and low change in changing attitude toward ADHD as the participants scored significantly higher on Knowledge, behavioral interventions, and significantly low score on changing attitude towards ADHD.

Wienen et al., [25] also examined teachers' attitudes towards children with $\mathrm{AD} / \mathrm{HD}$ and found that 152 out of the 196 teachers $(77.5 \%)$ believed that students with AD/HD should be placed in special education settings and that such a setting would be more favorable than a regular classroom. in the current study, the majority $(80.0 \%)$ of teachers were graduates of general education and didn't receive any training regarding handling ADHD children behaviors which may give an interpretation for the obtained results. As the general education regular classes have more than 26 students in each so, when there is a child with ADHD at one of these classes, the teachers either they can't deal with their abnormal attention and behavior or neglect them. Accordingly, during the data collection teachers reported that, the conducted educational training is the first one who include the behavioral practices regarding to how to deal with ADHD children during the lecture, exams and activities throughout their educational learning process. As the learned behavioral interventions had given them with the essential alternative strategies to be applied with ADHD children when they were included in their regular classes.

In fact, the most negative attitudes towards including students with $\mathrm{AD} / \mathrm{HD}$ in regular classrooms were yielded in a study conducted by Yoo et al. [28] with 164 preschool teachers in South Korea. Their findings indicated that, 97.6\% of teachers thought children with $\mathrm{AD} / \mathrm{HD}$ should be taught in special rather than regular education classrooms. Similarly, Nur and Kavakci [29] who explored the attitudes towards inclusion of 87 elementary school teachers in Turkey, found that most respondents $(93.1 \%)$ preferred special rather than general education placements for students with AD/HD.

On the other hand, Sarraf et al [30] showed that long term training and education through workshop was more effective in changing teachers attitude and rise teachers' knowledge of function with ADHD students. Moreover, Syed and Hussein [31] found that there was a significant improvement in teachers Knowledge about ADHD even after 6 month of training with pre mean score (10.7 $\mathrm{SE} \pm 0.29), \mathrm{t}=37.389$ at $\mathrm{P}$. $\mathrm{V}(.000)$, and post (13.4 SE \pm 0.36$), \mathrm{t}=37.572$ at $\mathrm{P} . .000$ for knowledge, attitude and behavior strategies among teachers of primary school.

As regard to the correlation between knowledge, attitudes and behavioral practices and participants' demographic background, there were no significant relation between all teachers demographics with their knowledge, attitude, and behavioral practices in both pre and post, except for who attending an in-service presentation on ADHD in post behavioral practice assessment at $\mathrm{p}=.004$. Similar results was obtained by khalil and Abdelwahab [23]; Mirza, Nisar, Ikram [32] and Rodrigo et al, [33] in their study as they found that, only special training in ADHD was an important factors affecting level of knowledge and attitudes.

To the best of our knowledge, this study may be the first interventional study conducted at these governmental schools as the teachers seemed that they may listen before about the topic despite some of them face some form of students with ADHD behavior and they respond by just called the parent of the child without any scientific interventions from the teachers side. Moreover, many teachers in the current study not only understood that, their knowledge was poor, they also identified responsibility in detecting, treating ADHD and providing extra educational assistance to those children. In Saudi Arabia, teachers do not have specific training about ADHD; rather, they have complete modules on educating special needs children as one element of their bachelor's degree in Special Educational Needs [34]. Therefore, the teachers learning experiences which address issues such as ADHD, their practices are predominantly formed from direct classroom interaction with students with ADHD. This is an encouraging sign for the future and emphasizes the importance of providing teachers with preservice or inservice training on common childhood psychological problems including ADHD. Therefore, teachers need to know how to apply their knowledge in order to have successful results and should has positive attitude with child who diagnosed with ADHD. 
Moreover, the findings (Table 6) revealed that there was no significant correlation between all measurements scale except for the presence of statistically significant correlation between teachers' attitude in post assessment with their behavioral practices in post assessment at $\mathrm{r}=.012$ and their behavioral practices in pre assessment with their post assessment at $r=.005$. In the present study, the absence of significant effects of age and years of teaching experience on attitude may be explained the fact that neither experienced nor beginning teachers receive training concerning students with special needs and inclusive education in their professional preparation programs. Therefore, despite their different levels of experience, the teachers' attitudes towards inclusion may be the same Similarly, Latouche and Gascoigne [24]; Alamri, [6] and Legato, [35] reported that, their educational interventions were effective in increasing teachers' self-efficacy in dealing with ADHD children. The absence of a significant correlation between prior experience with students with AD/HD-related behaviors and teachers' attitudes in the present study supports the view that having experience with persons with disabilities does not lead to positive attitudes on its own [36-38]. Alamri [6] reported that, a number of academic researchers in Saudi Arabia which was conducted in the field of disability studies have come to a consensus that even though students with $\mathrm{AD} / \mathrm{HD}$ attend regular schools, most of these schools lack appropriate educational strategies to serve such students effectively [39]. In the same vein, Weisel and Dror [40] examined the effects of 139 primary teachers' behavioral practices on their attitudes towards inclusion. The authors found that teachers who were more efficacious in practicing behavioral interventions had more favorable attitudes towards ADHD children integration in their regular classes While, Khalil and Abdelwahab [23] reported that, teachers' age was significantly correlated with their attitudes toward managing ADHD students when they were present in their classes.

Many studies explained the relationship between attitudes and behavior as the human behavior is guided by attitudes. Accordingly, Fischbein's and Ajzen [41] produced a model with called the 'theory of reasoned action'. This theory is an excellent model that explain observed links between attitudes and behaviors. The theory of reasoned action suggests that the cause of behavior is a person's intention to engage in the behavior. Attitudes influence behavior by their influence on intentions, which are decisions to act in a particular way. The issue of how an attitude was transformed into action was resolved by adding direct learning experience, which lead to the formation of an intention. An intention was explained to be the person's motivation to exert effort to carry out a behavior. On the contrary, people with negative attitudes tend to think that situations are harder than they really are and thus may choose to avoid such rebellious situations $[42,6]$. This implies that teachers who were effectively dealing with ADHD students and their related behaviors are more likely to hold a positive attitudes about the integration of those students in their regular classrooms and that teachers who doubt their proficiencies tend to believe that, such interactions might be difficult and demanding and thus, may exclude such students to be included in their classrooms.

\section{Conclusion}

The present study revealed that a brief professional educational intervention can be utilized to greatly increase teachers' ADHD knowledge, providing a cost-effective, practical solution to address this well-evidenced gap in teachers' training and knowledge about the ADHD disorders. The results showed that, teachers' knowledge was low regarding the symptoms, causes and treatment modalities of ADHD but they have reasonable information about ADHD general characteristics.

As regard to the attitude components, the results of the current study showed that in pre assessment, teachers hold negative or ambivalent attitudes toward teaching children with ADHD or including them in their regular classes. While, a post assessment results indicate that training and educational interventions help in raising teachers' awareness for developing favorable attitudes and beliefs. Although, changing teachers' attitudes were little with no significant difference between pre/post assessment.

Moreover, as regard to the behavioral practices, the study demonstrated that there was highly statistical significant difference between pre and post assessment score on behavioral interventions scale among group. In addition to, the current study illustrated the positive significant correlation between behavioral and attitudes of teachers toward inclusion of ADHD in their regular classrooms. Accordingly, the more the positive attitude held by the teachers, the more the behavioral interventions practiced by them.

On the other hand, the current study indicated that teachers' demographic background (age, teaching experiences) had no significant influence on their knowledge, attitudes, and behavioral practices except for those who attended in-service training previously with a significant difference between pre and post intervention in relation to their knowledge and attitudes.

\section{Recommendations}

Based on the findings of the current study the following recommendations will be as following:

Incorporating ADHD training programs into teachertraining curricula either in in special or general education, with regular reinforcement through in-service training.

Ministry of Art and education needs to take a more proactive approach by designing and conducting Specialized in-service training courses for primary school teachers in order to increase recognition and awareness of these disorders. 
Future research should be directed toward conducting similar study with large sample size and follow up long term assessment in order to examine the retention of teachers' knowledge and the competency level in applying the behavioral strategies in managing children with ADHD.

\section{Limitation of the Study}

While this study provided information to the area of teachers' knowledge, attitudes and behavioral strategies used with ADHD in 4 different schools located in Saudi Arabia, number of limitations may reduce the generalizability of the study findings as the followings:

Small sample size which limits the generalizability of the study findings. However, the higher response rate of teachers may raise the ability to generalize the results.

Another important limitation was that the sample of participants was only female which made the applicability of these results to male teachers might be limited.

This research is also limited by the use of correlation analysis and convenience sampling technique. This type of sampling and statistical analysis provides understanding the nature of relationships between variables, but it does not indicate what causes the relationship which limits drawing conclusions about outcomes and causes.

\section{Acknowledgements}

The researchers would express their sincere gratitude and great appreciation to the principals and teachers of the included schools for their sustainment help and cooperation during data collections.

\section{References}

[1] Ali Munshi AM. Knowledge and Misperceptions towards diagnosis and management of attention deficit hyperactivity disorder (ADHD) among Primary School and kindergarten female teachers in Al-Rusaifah district, Makkah city, Saudi Arabia. Int J Med Sci Public Health 2014; 3 : 434-441.

[2] Homidi, M., Obaidat, Y., \& Hamaidi, D.. Prevalence of Attention Deficit and Hyperactivity Disorder among Primary School Students in Jeddah city, KSA. (2013) Retrieved from http://www.lifesciencesite.com/lsj/life1003/044_19518life100 3_280_285.pdf.

[3] Saad, S., \& Lindsay, G. Preschool children with Attention Deficit Hyperactivity Disorder (ADHD) in inclusive settings: Challenging but not problematic. Journal of Social Sciences \& Humanities, (2010).18 (1), 115-132.

[4] American Psychiatric Association. Diagnostic and statistical manual of mental disorders: DSM-5 (5 ed.). 2013; Arlington, VA: American Psychiatric Publishing.

[5] S Mehta, et al, Peer-Mediated Multimodal Intervention Program for the Treatment of Children with ADHD in India: One-Year Follow-upISRN Pediatr, 2012; 419168-
419168.

[6] Alamri S., Students With ADHD-Related Behaviors: Saudi Mainstream Teachers' Knowledge And Attitude Towards Inclusion. published thesis of $\mathrm{PhD}$, Office of Education Research.2014; Faculty of Education Queensland University of Technology.

[7] Khademi, M; Rajeziesfahani, S; Noorbakhsh, S; Panaghi, L; Ashtiani, M; Razjouyan, K \& Salamatbakhsh, N. Knowledge and Attitude of Primary School Teachers in Tehran/Iran towards ADHD and SLD, Global Journal of Health Science.2016; Vol. 8, No. (12): 141-149.

[8] Alkahtani, K.. Teachers' Knowledge and Misconceptions of Attention Deficit/Hyperactivity Disorder. Psychology, 2013; 04 (12), 963-969. doi: 10.4236/psych.2013.412139.

[9] Salamatbakhsh, N., Khademi, M., Noorbakhsh, S., Rajeziesfahani, S., Davari-Ashtiani, R., \& Razjouyan, KInvestigating the Knowledge and Attitude of Primary School Teachers in Tehran towards Attention-Deficit/Hyperactivity and Learning Disorders and Relation to Teacher's Characteristics. Scientific Journal of Rehabilitation Medicine, 2016; 5 (3), Under Press.

[10] Peters, G.-J. Y.). The alpha and the omega of scale reliability and validity: Why and how to abandon Cronbach's alpha and the route towards more comprehensive assessment of scale quality. European Health Psychologist, 2014; 16 (2), 56-69.

[11] Lasisi, D., Ani, C., Lasebikan, V., Sheikh, L., \& Omigbodun, O. Effect of attention-deficit-hyperactivity-disorder training program on the knowledge and attitudes of primary school teachers in Kaduna, North West Nigeria. Child And Adolescent Psychiatry And Mental Health, 2017; 11 (1). doi: 10.1186/s13034-017-0153-8.

[12] Shehata, A., Mahrous Abd El Aziz, E., Abd El latif Farrag, E. and Hassan Hassan, Z. Effectiveness of Structured Teaching Program on Knowledge, Attitude and Management Strategies Among Teachers of Primary School toward Children with Attention Deficit Hyperactivity Disorders. (2016); [online] Pdfs. semantic scholar. org. Available at: https://pdfs.semanticscholar.org/8c7c/1e3f849fd60c92968a 38c8127ba3dc23c50a.pdf [Accessed 5 May 2019].

[13] Alhraiwil, N., Ali, A., Househ, M., Al-Shehri, A. and Elmutually, A. Systematic review of the epidemiology of attention deficit hyperactivity disorder in Arab countries. (2015); [online] Available at: https:// ww.ncbi.nlm.nih.gov/pmc/articles/PMC4727626/[Accessed 3 Feb. 2019].

[14] School Interventions - CHADD. (2019). Retrieved from https://chadd.org/for-parents/school-interventions/

[15] Sciutto, M. J., Terjesen, M. D., \& Frank, A. S. B. Teachers' knowledge and misperceptions of attention-deficit/hyperactivity disorder. Psychology in the Schools, (2000); 37 (2), 115-122. doi: 10.1002/ (sici) 15206807 (200003) 37: 2<115:: aid-pits3>3.0.co; 2-5

[16] Perold, M., Louw, C., \& Kleynhans, S. Primary school teachers' knowledge and misperceptions of attention deficit hyperactivity disorder (ADHD). South African Journal of Education, 2010; 30 (3), 0-0. 
[17] AUSTERMAN, J. ADHD and behavioral disorders: Assessment, management, and an update from DSM-5, 2015; VOLUME 82. Retrieved from https://mdedge-files-live.s3.useast-2.amazonaws.com/files/s3fs-

public/issues/articles/Austerman_ADHD.pdf.

[18] Sciutto, M. J., \& Eisenberg, M.. Evaluating the evidence for and against the over diagnosis of ADHD. Journal of Attention Disorders, 2007; 1, 106-113. http://dx.doi.org/10.1177/1087054707300094

[19] Soodak, L. C., Podell, D. M., \& Lehman, R. Teacher, student, and school attributes as predictors of teachers' responses to inclusion. The Journal of Special Education, 1998; 31 (4), 480-490.

[20] Matlock, E. A. Differences in elementary school teachers' instructional environment and perceived competence toward children with Attention Deficit Hyperactivity Disorder as a function of attitudes toward control versus autonomy, training, and experience.1999; Unpublished doctoral dissertation, Oklahoma State University, OK.

[21] Small, S. Attention-deficit/hyperactivity disorder: General education elementary school teachers' knowledge, training, and ratings of acceptability of interventions. 2003; University of South Florida. Retrieved from http://scholarcommons.usf.edu/cgi/viewcontent.cgi?article $=24$ $78 \&$ context $=$ etd

[22] Kline, R. B. Principles and practice of structural equation modeling.2010; (3 ed.). New York: Guilford Press.

[23] Khalil A., and Abdelwahab S. Effectiveness of an Educational Intervention on Improving Elementary School Teachers' ADHD Knowledge, Attitudes and Self-Efficacy. Saudi Journal of Nursing and Health Care; 2019; vol. 2 issue (4): 152-167

[24] Latouche1 A., and Gascoigne M., In-Service Training for Increasing Teachers' ADHD Knowledge and Self-Efficacy. Journal of Attention Disorders. 2017; pp. 1-12 sagepub.com/journals Permissions. nav DOI: 10.1177/1087054717707045 journals.sagepub.com/home/jad

[25] Wienen, A., Batstra, L., Thoutenhoofd, E., de Jonge, P., \& Bos, E. Teachers' perceptions of behavioral problems in Dutch primary education pupils: The role of relative age. PLOS ONE, 2018; $13 \quad$ (10), e0204718. doi: 10.1371/journal.pone.0204718.

[26] Veenman, B., Luman, M., \& Oosterlaan, J. Further Insight into the Effectiveness of a Behavioral Teacher Program Targeting ADHD Symptoms Using Autography, Classroom Observations and Peer Ratings. Frontiers In Psychology, 8. doi: 10.3389/fpsyg.2017.01157.

[27] White, S., Sukhodolsky, D., Rains, A., McGuire, J. and Scahill, L. Elementary School Teachers' Knowledge of Tourette Syndrome, Obsessive-Compulsive Disorder, \& Attention-Deficit/Hyperactivity Disorder: Effects of Teacher Training.2010; [online] Research gate. Available at: https://www.researchgate.net/publication/226497217_Element ary_School_Teachers'_Knowledge_of_Tourette_Syndrome_O bsessive-Compulsive_Disorder_AttentionDeficitHyperactivity_Disorder_Effects_of Teacher_Training [Accessed 5 May 2019].

[28] Yoo, I. Y., Ra, J., Oh, E., \& Kim, M. Knowledge and attitude to Attention Deficit Hyperactive Disorder in Korean preschool teachers. Journal of Korean Academy of Child Health Nursing, 2009; 15 (4), 383-391.
[29] Nur, N., \& Kavakci, O. Elementary school teachers' knowledge and attitudes related to attention deficit hyperactivity disorder. Health MED, 2010; 2 (4), 350-355.

[30] Sarraf N., S. A comparative study of the effectiveness of nonattendance and workshop education of primary school teachers on their knowledge, attitude and function towards ADHD students in Isfahan in 2010. [online] PubMed Central (PMC). 2019; Available at: https://www.ncbi.nlm.nih.gov/pmc/articles/PMC3430045/ [Accessed 5 May 2019].

[31] Syed, E. and Hussein, S. Increase in Teachers' Knowledge About ADHD After a Week-Long Training Program: A Pilot Study - Ehsan Allah Syed, Sajida Abdul Hussein, 2019; [online] SAGE Journals. Available at: https://journals.sagepub.com/doi/abs/10.1177/1087054708329 972 [Accessed 5 May 2019].

[32] Mirza N, Nisar N, Ikram Z. Knowledge, attitude \& practices towards attention deficit hyperactivity disorder among private elementary school teachers of Karachi, Pakistan. J Dow Uni Health Sci 2017; 11 (1): 11-17.

[33] Rodrigo MD, Perera D, Eranga VP, Williams SS, Kuruppuarachchi KA. The knowledge and attitude of primary school teachers in Sri Lanka towards childhood attention deficit hyperactivity disorder. The Ceylon medical journal. 2011; 56: 51 .

[34] Alabd AM, Mesbah SK, Alboliteeh M. Effect of Educational Program on Elementary School Teachers" Knowledge, Attitude, and Classroom Management Techniques Regards Attention Deficit Hyperactivity Disorder. International Journal of Studies in Nursing. Jul 2018; 30; 3 (3): 159.

[35] Legato, L. J. Effects of teacher factors on expectations of students with ADHD (College of Liberal Arts \& Social Sciences Theses and Dissertations, Paper 66) 2011;. Retrieved from http://via.library.depaul.edu/etd/66.

[36] Avramidis, E., \& Norwich, B. Teachers' attitudes toward integration/inclusion: A review of the literature. European Journal of Special Needs Education, 2002; 17 (2), 129-147. doi: $10.1080 / 08856250210129056$.

[37] Hayashi, R., \& May, G. E. The effect of exposure to a professor with visible disability on students' attitudes toward disabilities. Journal of Social Work in Disability and Rehabilitation, 2011; $10 \quad$ (1), 36-48. doi: 10.1080/1536710X.2011.546300.

[38] Shannon, C. D., Tansey, T. N., \& Schoen, B. The effect of contact, context, and social power on undergraduate attitudes toward persons with disabilities. Journal of Rehabilitation, 2009; 75 (4), 11-18.

[39] Alothman, S. Children with AD/HD.. Solutions are not implemented! AL Riyadh Newspaper. 2011a;. Retrieved from http://www.alriyadh.com/2011/01/29/article599204.html

[40] Weisel, A., \& Dror, O. School climate, sense of efficacy and Israeli teachers' attitudes toward inclusion of students with special needs. Education, Citizenship and Social Justice, 2006; 1 (2), 157-174. doi: 10.1177/1746197906064677.

[41] Fishbein, M. \& Ajzen, 1. Belief attitude, intention, and behavior.- an introduction to theory and research. Reading, MA: 1975; Addison-Wesley. 
[42] Bandura, A. (1994). Self-efficacy. In V. S. Ramachandran (Ed.), Encyclopedia of human behavior (Vol. 4, pp. 71-81). New York: Academic Press. (Reprinted from: H. Friedman [Ed.], Encyclopedia of mental health. San Diego: Academic Press, 1998). 